\title{
Applicability domain for classification problems
}

\author{
lurii Sushko*, S Novotarskyi, AK Pandey, R Körner, Igor Tetko \\ From 5th German Conference on Cheminformatics: 23. CIC-Workshop \\ Goslar, Germany. 8-10 November 2009
}

Classification models are frequent in QSAR modeling. It is of crucial importance to provide good accuracy estimation for classification. Applicability domain provides additional information to identify which compounds are classified with best accuracy and which are expected to have poor and unreliable predictions. The selection of the most reliable predictions can dramatically improve performance of methods while decreasing coverage of predictions [1].

In binary classification problems, labels for machine learning methods are discrete $\{-1,1\}$. Nonetheless, model usually yields prediction that is continuous. Most apparent metrics for accuracy estimation is distance between prediction point and edge of a class, i.e. the more is the distance between prediction the edge of the class, the more reliable and accurate is the prediction of given compound. This metric has been already used in several previous studies (e.g., [2]) and demonstrated good separation of reliable and non-reliable classifications. In quantitative predictions, the standard deviation of ensemble predictions has been found as the most accurate measure distance in a recent benchmarking [3].

We propose to integrate both metrics. Rather than giving a point estimate, this approach provides us with a probability distribution of finding particular compound in one of the classes. Suggested metrics is probability

$$
\int_{E} N(a, v, x) d x
$$

where $E$ is class domain $a$ - ensemble's average prediction, $v$ - variance of ensemble's prediction, $N(a, v, x)$ is probability density of the Gaussian distribution. Performance of this metric and its comparison to the traditional ones are evaluated for several QSAR/QSPR

Sushko, I., Helmholtz Zentrum München/IBIS, Ingolstädter Landstraße 1, D-85764 Neuherberg, Germany classification problems. The developed approach can be freely accessed to develop and estimate applicability domain of classification models at http://qspr.eu web site.

Published: 4 May 2010

\section{References}

1. Tetko IV, Bruneau P, Mewes HW, Rohrer DC, Poda Gl: Drug Discov Today 2006, 11:700.

2. Manallack DT, Tehan BG, Gancia E, Hudson BD, Ford MG, Livingstone DJ, Whitley DC, Pitt WR: J Chem Inf Comput Sci 2003, 43:674.

3. Tetko IV, Sushko I, Pandey AK, Zhu H, Tropsha A, Papa E, Oberg T, Todeschini R, Fourches D, Varnek A: J Chem Inf Model 2008, 48:1733.

doi:10.1186/1758-2946-2-S1-P41

Cite this article as: Sushko et al:: Applicability domain for classification problems. Journal of Cheminformatics 2010 2(Suppl 1):P41.

\footnotetext{
Publish with ChemistryCentral and every scientist can read your work free of charge

"Open access provides opportunities to our colleagues in other parts of the globe, by allowing anyone to view the content free of charge." W. Jeffery Hurst, The Hershey Company.

- available free of charge to the entire scientific community

- peer reviewed and published immediately upon acceptance

- cited in PubMed and archived on PubMed Central

- yours - you keep the copyright

Submit your manuscript here:

http://www.chemistrycentral.com/manuscript/

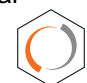
Chemistry Central
} 